This is an author-produced PDF of an article published in Research Studies in Music

Education. The definitive version is available online and the citation information is:

Wolfe, J. (2018). An investigation into the nature and function of metaphor in advanced music instruction. Research Studies in Music Education.

https://doi.org/10.1177/1321103X18773113

\title{
An investigation into the nature and function of metaphor in advanced music instruction
}

\author{
Jocelyn Wolfe \\ Griffith University, Australia
}

\begin{abstract}
Metaphors are an important linguistic device that can enable music teachers to explain expressive performance features in a way that makes sense to their students. This study extends the limited literature on the application of metaphors within advanced music instruction, providing new insights into the nature and function of metaphor in the way that music is perceived, performed and taught. It is based on an investigation of 80 hours of teacher instruction recorded across five instrument areas: strings, woodwinds, brass, percussion and keyboard. Metaphors were identified, analysed in relation to contextual meanings, and explored in relation to relevant literature. The findings suggest that with attentive use, metaphors can be useful "bridges to learning" in music instruction contexts.
\end{abstract}

\section{Keywords}

metaphor, music instruction, music perception, psychology of music, studio music teaching

\section{Introduction}

Metaphor is characterised as a bridge to learning (Cortazzi \& Jin, 1999), not least in a mediating role between teacher and learner by enabling subjective interpretations to be shared in the pursuit of intersubjectivity. Musical sound is open to such subjective interpretation. One way we perceive qualities of musical sound is by mapping, potentially through neural pathways, experience of the physical world onto the intangible aspects of sound. These mappings are mediated through language and are essentially what constitute metaphors in this context. For example, a teacher might attempt to explain timing, in the sense of a pause, by saying, "It's that moment when you twist the knife". This article seeks to answer a number of pedagogical questions, based on detailed observations of metaphors employed in 80 hours of classical music instruction. It will explore the dimensions and features of metaphors in this context and how systematic they; how metaphor elucidates 
aspects of musical sound and what motivates this; and what relevance this has to the studio music teacher.

Many studies on the use of metaphor in relation to classical music discourse focus on how it is used to characterise melody, harmony and other structural features of the musical score to give the music meaning. Other studies investigate the interrelation of language, cognition, perception and performance. What is missing are more studies on the use of metaphor in realworld music instruction settings in order to:

- enhance our understanding of the musical functions of metaphors (Eitan \& Rothschild, 2011; Juslin, 2003);

- explore the richness of human musical experience "without trying to control or limit it" (Sloboda, 2008, p. 33); and

- clarify the kinds of empirical evidence needed to properly characterise the reaches and limits of metaphor in such specialised contexts (Gibbs, 2008).

Of particular interest to music educators is Schippers' (2006) call for a breadth of research on metaphor to facilitate creative and expressive practice in music performing, learning and teaching. Satisfying these calls to action requires pedagogical studies that engage with the complexity of metaphor use in music instruction.

Studio music lessons provide the best opportunity to investigate these issues, as metaphor is central to the language of instruction (see Juslin, 2003; Karlsson, Liljeström, \& Juslin, 2009; Laukka, 2004; Lindström, Juslin, Bresin, \& Williamon, 2003; Van Zijl \& Sloboda, 2010; Woody, 2000). Here, the teacher imparts to the student their own learned experience of the music - the form, style, and "character" that the composer incorporates into the score, and importantly, the means of expressing this in performance. In this context, the function and nature of metaphor can be examined more closely in relation to its pedagogical role.

\section{Metaphor and learning expressivity}

Psychologists working on expressivity largely assert that expression in performance is intrinsically connected to human emotion. According to Woody (2000), attention to performer felt emotion seems to have an established place in the expressive training of student musicians. In his study of how college students learn expressivity in performance, most indicated that they learnt it through verbal-based instruction in their college music lessons. Lindström et al. (2003) found that most students ranked metaphor as the best strategy for teaching expressivity, with felt emotion and aural modelling next. This contrasts with Laukka's 2004 study, where teachers from conservatories in Sweden and England were asked to rank their methods for teaching expressivity according to metaphors, aural modelling and felt emotion. Modelling was ranked first, felt emotion second, and metaphor use third. Other studies (Sheldon, 2004; Karlsson et al., 2009) however, have shown the great extent to which the verbal instructions of music teachers feature metaphor. Further to this, Juslin, Friberg, Schoonderwaldt, and Karlsson (2004) even consider that the usefulness of metaphor in music teaching is primarily in connecting the emotional content of music.

With the common perception that musical expression has a close connection to emotion (see, e.g., Laukka, 2004; Lindström et al., 2003; Woody, 2000), it is possible to be persuaded to go no further than look for how and whether this is made explicit in the verbal instructions of music teachers. However, the last decade has also seen an emergence of empirical studies 
which show that emotion is not the only entailment of musical expression - a perspective that Juslin (2003), Lindström et al. (2003) and Laukka (2004) advanced, and other research has shown more explicitly (see Eitan \& Granot, 2006; Eitan \& Rothschild, 2011; Eitan, Schupak, \& Marks, 2008).

Evident from many of these studies is the view that expressivity is learned, which implies that expressive skills can be taught (Swanwick, 1979), and that explicit instruction is beneficial to learning expressive skills (see Juslin \& Laukka, 2000; Juslin \& Persson, 2002; Woody, 1999). Further, the use of metaphors is a popular teaching strategy aimed at developing expressivity (Barten, 1998; Woody, 2002).

What is it about metaphor beyond the level of linguistic communication of an association that serves its instructive purpose in music? Sloboda's theory on the acquisition of musical performance expertise helps explain this. Sloboda raises the idea of extramusical templates, "extra-musical functions and formulas that act as ready-made templates onto which musical expression can be mapped" (1996, p. 288). Woody postulates further that performers use such templates as a memory aid in programming changes in timing, loudness, and intonation. He continues:

It would be too cumbersome for a musician to remember and retrieve vast amounts of detailed performance operations each time, for example, a ritardando is to be performed. Instead, musicians can more efficiently handle the information by abstracting it into a single extramusical analogy. (Woody, 2000, p. 15)

Extrapolating on this idea, I propose that metaphorical associations are pathways to extramusical templates onto which details of the musical aspects of the expressive performance that are too "cumbersome" to remember and retrieve, can be mapped. The image of a flock of birds taking to the sky, for example, may encapsulate a change in dynamics and tempo in a particular passage. Questions arise then as to what borrowings or cross-domain mappings (extramusical associations to aspects of musical sound) are drawn on in teaching expressivity through metaphoric association.

My study provides some answers to the calls for action previously mentioned, highlighting the complex nature of metaphor in this context. It also brings a different perspective to the discussion of teaching expressivity which has, on the whole, centred on the emotional content of musical meaning in relation to expressive playing.

\section{The research design}

\section{Participants}

The study investigated the specialised use of metaphor in music instruction by collecting new data and examining the less surveyed spoken discourse of advanced music lessons.

Specifically, the study showed what meanings and messages were being conveyed in teacher talk by collecting and analysing samples of metaphorical language used in teaching instrumental music across the broad genre of western art music. It took as its principal sources music lessons and rehearsals at Queensland Conservatorium Griffith University (2008-2011), one of the two largest conservatoires in Australia, and the Australian Youth 
Orchestra National Music Camp (2010), a total immersion initiative for promising young musicians.

The instructional settings included one-on-one lessons, small ensembles, and large ensembles. Advanced instructional settings were chosen for the likelihood of teaching goals concerning performance excellence and expressivity, as opposed to note learning and technique. These instructional settings represent a situation in which the greater proportion of speaking is done by the teacher/conductor, maximising the amount of comparable data (in this case, spoken expression of metaphor). In this way, more than 80 hours of instruction were recorded across five major instrument areas (strings, woodwinds, brass, percussion, and keyboard), with an average of about four hours per teacher. Audio-recordings of the sessions, which vary in length from 40 minutes to two hours, were transcribed, and the transcriptions harvested for remarks containing metaphorical language. The musical repertoire was not identified in the collection except to acknowledge that it fell within the framework of western art music. Additionally, instrumental instruction was chosen over vocal instruction to avoid confusing intentional or unintentional metaphorical associations arising through lyrics.

\section{Identifying and analysing metaphor}

A metaphor identification procedure (see Steen et al., 2010) was employed to understand what the metaphorical language revealed about the way teachers elicit expressive playing in their verbal communication with students. This involves determining what word or words in a remark may be the vehicle of a metaphor, the root of its extramusical association (source domain), and what this refers to musically (the musical topic). This is done by looking for chunks or stretches of language that might be metaphorical due to the presence of a word or words that are somehow incongruous within the ongoing discourse context. From this, a contextual meaning is understood. Steen et al. (2010) explain that the contextual meaning may be conventionalised and attested, and will then be found in a general user's dictionary, but it may also be novel, specialised or highly specific to the situation, in which case it cannot be found in a general user's dictionary. Commonly, the contextual meaning points to the topic, and the vehicle is a word or phrase that links to a whole conceptual domain which may be "visualised" or activated through the association of its more basic (what might otherwise be called literal) meaning. The incongruity can therefore be seen to arise between the contextual meaning and the basic meaning.

As expressive elements of music performance concern acoustic and temporal aspects of musical sound only these were considered as topics. This included acoustic aspects of playing (e.g., tone), temporal features of performance (e.g., timing), and means of expressing the sound (e.g., articulation). While melody and harmony cannot be altered in performance, except by error, how these are sounded by the player varies a great deal, the consequence of which contributes to differences in expressive performance; the "interpretations" of which Juslin speaks (2003, p. 275). A remark could be identified as expressive-related when it sought to explain or clarify how the music should sound. So the remark, "It's like making a cake. If you are stiff, you will be exhausted after one cake" metaphorically pertains to an issue of physical action that has a resulting physical condition and could therefore be excluded. On the other hand, "Stick your bow into the string, we want some punch" has a sense of the desired sound and so could be retained.

To elucidate the extramusical meaning conveyed in the metaphor (what meaning it was ascribing to the musical topic), the vehicle was then surveyed through a semantic field. For 
example, in an expression like "Hold the tempo at bar 45!" the vehicle for the metaphor is "hold". It refers to tempo in the topic domain and has semantic connections to "grasp", "grip", and "embrace", for example, through the semantic field pertaining to "hold". Through this family resemblance we see how tempo is perceived as an object or an animal-a runaway horse, and how one might control it. All semantic associations at this stage were sourced from reputable general user dictionaries.

If a musical topic was frequently referred to through the semantic field of one source domain, a systematic metaphor was proposed. For example, most teachers in the study instructed on the musical aspect of tempo using the following metaphor vehicles: "push it", "pull it back", "drop it", "hold it", and it can also "get away" or "drag". Such usage points to an underlying concept, TEMPO IS AN OBJECT OR ANIMAL, and that this concept is sufficiently systematic as to be conventional for the speakers in the study. However, "put the brakes on" was a more creative application on a linguistic level. In this way, a sense of systematic and more creative metaphors could be gained.

Identifying issues concerning metaphor analysis as determined by key metaphor researchers (see Steen et al., 2010) permitted a methodical approach to the problematic task of identifying, coding, and classifying metaphor and steered this research towards a reliable and reproducible approach to the analysis of metaphor in the verbal language of music instruction.

\section{Key lessons on metaphor in music instruction}

From the transcriptions, I identified over 900 remarks containing examples of metaphors (including similes and analogies) and described 815 vehicle terms with certainty. These were initially classified into linguistic groups:

- word classes included nouns, verbs, phrasal forms (containing prepositions), adjectives, adverbs and phrase forms (where the vehicle was a small group of words representing one conceptual unit)

- narrative trails, where larger chunks of language represented one conceptual unit

- analogies, where the vehicle was marked by the words "like" or "as".

Certain types of linguistic forms were much more prevalent in the data than other types. For example, the noun and adjective word classes were most prevalent, followed by verb forms.

There is little doubt that the range of vehicle terms, on the whole, appears to represent a great diversity of associations - too many to draw conclusions about the systematic application of particular associations with particular musical aspects. However, by assembling the vehicle terms into semantic fields that could be shown to have common source domains; systematic associations became apparent for these metaphors in relation to acoustic and temporal aspects of musical sound, as well as for the expressive devices (the means by which expressive playing is facilitated).

Of the 815 vehicle terms, only 27 were found to be listed with a separate, more contemporary and specifically musical sense, in the general user dictionaries consulted in this study. They included: abrasive, bloom (verb), bouncy, brassy, bright, colour (noun), crack (noun), dark, dry, edge, entry, fruity, full-bodied, fullness, line, muddy, palette, rich, round, scratchy, shape (verb), sweet, swell (noun), thick, thin, top, and woolly. Of these, only abrasive, 
colour, dark, palette and round were further qualified as figurative. Yet the analysis showed that for all of these words, there was evidence of cross-domain mapping indicative of metaphorical use found as a result of either comparing basic and contextual meanings, or identifying incongruity between the vehicle term and the ongoing discourse. Other vehicle terms commonly used by teachers in this study were not listed as having a musical sense in general user dictionaries. These included: breathe, bring out, colour (the verb), come back, come in, come out, cut through, direction, feminine, flow, heavy, hold, in, masculine, on, out, push, shape, speak, and stretch out.

While Steen et al. (2010) found that most contextual senses for vehicle terms in everyday usage are listed in dictionaries; many contextual meanings in this study were not, and so new meanings had to be educed. Discerning contextual meanings from basic meanings did not always provide clarity. Meaning is ultimately dependent on how the participants in a discourse construe it, as well as on acculturation and enculturation processes (Schippers, 2010). More might be learned from studies that explicitly incorporate a participant's understandings, but this has problems. In the real-time processing of instructions in the music lesson, such verbal negotiation is rarely engaged in, and the contextual meaning must more often be construed from pragmatic information. This concurs with Gibbs (2002) who argued that people utilise pragmatic information over semantic information when interpreting any utterance. While my current study did not extend to an analysis of real-time processing, it is noteworthy that the speakers and listeners (music teachers and students) are likely to be highly attuned to the specialised context, providing them pragmatic, contextual information in the discourse.

The overall predominance of musical topics was calculated by establishing the frequency with which each appeared uniquely, and importantly, when it paired with one or more other topics. For example, while "dynamics" was the most predominant topic overall, it was often accompanied by another musical topic apparent in the same metaphor. One metaphor vehicle could therefore be said to target more than one musical aspect in one remark. In this way, dynamics were often found to pair with tone, phrasing, articulation, tempo and timing. Other predominant single topics were articulation, timing and tone. Articulation was also identified as a common companion topic. For example, articulation often paired with dynamics, "If you use lots of bow it's going to make a big splash". Surprisingly, phrasing was prevalent as a single topic to a lesser degree. However, when issues of phrasing were dealt with, this frequently involved the dynamics of the sequence of notes. For example, "Now let's be quieter so you can give me an arch to the fizz note". Phrasing also correlated with timing: "Have a sense of the pacing of the rise and how long you should stay up there. Otherwise you don't get enough shape to the phrase".

This complexity raises another common feature of metaphor topics known as "diversification" (Goatly, 1997). Here, mapping from more than one source domain can construct the conceptualisation of a topic. For example, both the dimension and motion domains map strongly onto dynamic changes in a passage (the dynamics swell, build up and drop back), but so does the force/gravity domain (the dynamics can be held back, fall and drop). Dynamics also have physical properties (it fades, evaporates, and dissolves) and properties of life (it grows and dies). Complexity of this nature suggest a network of inter-relationships between topics and source domains for metaphor in this context. This confirms that aspects of musical sound that are commonly referred to discretely as tone, intonation, dynamics and so on, share common properties. This finding also supports Kövesces' claim that "we often need several source domains to understand aspects of target domains" (2010, p. 96). 
Establishing the predominant correlations between extramusical associations and musical topics ultimately drew attention to how metaphor elucidates the expressive properties of musical sound. It also showed what is conventional in the language and what is more creative, and established a pattern of systematic usage. In this regard, the expressive constituents of musical sound were found to predominantly associate with motion, dimension and force in their source domains. This supports what is generally proposed in the literature on metaphor and musical sound. What my research brings to light is the aspect of diversification for topics, as I have already raised, and additionally, the striking tendency towards multivalency in the source domains. Multivalency describes the property of one metaphor vehicle to work with different topics (Goatly, 1997). An illustration of this complexity is: "Think of it as a bloom point, where your sound blooms a little more". In the teaching sequence observed, the sense of "blooming" (opening), was meant to adjust specific musical aspects in the student's playing, including at least tone, dynamics and phrasing. The teacher was looking for an expressive sound which required adjustment of two specific acoustic properties and an expressive device.

It was in determining multivalency and diversification that the complex nature of metaphor became demonstrably clear. Cameron and MetNet Group (2006) describe the "complex, indeterminate, and unstable" nature of metaphor, and this must not be overlooked in relation to musical sound. However, ultimately, the complexity of metaphor responds well to the physically complex phenomenon of musical sound. We know that sounds are made up of a complicated mixture of vibrations, but musical sound has even more factors that complicate the sound signal at the level of a note or collection of notes. These factors include intensity, frequency, spectrum and time envelope. It seems likely then that metaphor is used for the very reason that the properties of sound are complexly correlated and the way we perceive musical sound similarly so. To capture all the "cumbersome" details, as Woody (2000, p. 15) put it, in a metaphor (or analogy), is an intuitive solution.

\section{Systematic usage}

A picture emerged from the study showing that acoustic topics that relate to tone (individually pitch, loudness and timbre) commonly associate with dimension, motion, force/gravity, picture/colour, illumination, physical and material qualities. Temporal topics (timing and tempo) are, not surprisingly, on the move as objects, people, cars, animals and water. And they can be physically controlled and respond to force. Expressive devices, such as articulation and phrasing, associate with painting a picture, illuminating an object, grasping something, navigating, reshaping and resizing something, and breathing and speaking.

The findings on systematic associations highlighted that certain vehicle terms are so highly conventionalised as to be no longer active metaphorically. These terms have become subsumed in sub-technical language and while they remain instructional, a greater instructional value was noted with metaphors that project away from conventional usage. They tended to be more personalised. And, importantly, they were likely to be deliberate and more powerful, perhaps used to follow-up a less effective instruction. For example, after instructing a student to "bring out" the melody in a Chopin nocturne did not produce the desired result, a teacher deployed a cluster of metaphor vehicles that provided more detail about the desired sound: 
You have to rearrange [the furniture] and put something here and there, and maybe a light next to the chair, so it looks nice. Same with the music. You don't want all the sound together. Separate the sound. Give the left hand its own space.

Referencing the rearrangement of furniture is a more novel linguistic application of the dimension metaphor. This type of deliberate vehicle development, fine tuning and clustering was observed in the study to be powerful not only in changing behaviour and eliciting the desired musical response, but also in instigating an interchange between teacher and student. As an affective stepping stone to understanding a musical goal, this type of metaphor should not be underrated in the role of building empathetic relationships in instructional settings.

Moving away from systematic usage, more novel metaphors were evident, some of which underline the potential for more poetic imaginings for musical sound, bringing humour and drama to the interaction. Some examples include:

Articulation (Pedal): [You used] so much pedal that it was swimming. The whole piece sounded like it was hosed.

Dynamics: It's like burning embers here.

Timing (a pause): It's that moment when you twist the knife.

Timing (beat, rhythm): Like the freeway you see across the river there ... you can see the beautiful line ... underneath that beautiful line are the pillars that hold the thing up. We need more of the pillars.

Having some insight into systematic and conventional associations for metaphors in relation to specific musical aspects raises the question of what falls outside those common associations - what is missing from the extramusical experience of musical sound. Further classification of the metaphor collection by way of their correlation to sensory reception domains revealed this. Most of the sensory reception domains (see Blakemore \& Jennett, 2001) were found to be immanent in this study, but the sense of smell was not. This may be explained by Williams' model of metaphorical transfer (1976), which demonstrates that "a systematic sequence exists in the application of sensory terms from a modality to another based on a hierarchy among the senses relative to the order in which they give or receive a semantic sense from other modalities" (as cited in Cacciari, 2008, p. 417). According to Williams' corpus (based on an analysis of synaesthetic adjectives), olfactory words are not transferable to other senses, (although it is interesting to note that Shakespeare's "If music be the food of love ... stealing and giving odour ..." from Act I, Twelfth Night, makes an exception). Such analysis is the province of psychophysics which "embraces the study of the subjective aspects of sensation in terms of objective stimulus energies" (Pfaffmann, 2017). A more detailed analysis of the data based on transfer across sensory modes would be necessary to advance explanations in this regard.

\section{Motivations for metaphor in relation to musical sound}

The applied linguistic approach employed in this study to identify and analyse metaphor in relation to musical sound is useful for highlighting dimensions of metaphor in relation to teaching expressive playing that may go unnoticed in studies from other pedagogical 
perspectives. The findings bring an appreciable insight into what underlies or motivates systematic mapping of certain source domains onto aspects of musical sound.

In contrast to Lippman's assertion that whatever the physical, biological, or sociocultural explanations of musical sound may be, its qualitative properties are "so various that they elude systematic classification" (1977, p. 43), the findings on systematicity are striking. The research demonstrates plausible systematic associations for sound, with many similarities to what are generally considered common source domains in everyday English, as outlined by Kövesces (2010), making the use of metaphor in this context consistent with everyday usage. However, it is what may be seen to motivate these systematic associations that brings relevance to the studio music teacher's usage. Many of our sensory experiences are fundamental to these associations and are ostensibly explained by real bodily experience (e.g., loudness is referenced by strength and physical dimensions), or perceived structural similarities (e.g., tone is referenced by colour).

The strong indications of systematic associations found in this study are consistent with research on psychophysical functions, which show that neural patterns in the brain connect with acoustic differences in musical sound, showing, in particular, neural links between physical stimuli including loudness, tempo, texture, and pitch, and the sensations and perceptions such stimuli affect (see Bhatara, Tirovolas, Duan, Levy, \& Levitin, 2011; Coutinho \& Cangelosi, 2009; Coutinho \& Dibben, 2012; Eitan \& Rothschild, 2011; Juslin \& Sloboda, 2001).

Arguably, metaphor is a direct expression of these sensations and perceptions (relative to the propositions of Lakoff \& Johnson, 1999). However, the complexity and diversity revealed in the metaphor source domains also shows that perceiving is accompanied by diverse personal and culturally shaped ways of feeling, sensing, and imagining musical sound. This is particularly apparent for dynamics. On the face of it, dynamics are concerned with the "intensity of volume with which notes and sounds are expressed" (Thiemel, 2016). However, dynamics bring together many of the properties of sound that are heard in a piece of music.

Going by the physics of sound, 'dynamics' is a term for the musical expression of loudness. And loudness (intensity) also has properties of pitch and timbre. As mentioned, dynamics were appreciably the most referred to topic of metaphor observed in this study. Dynamics were largely attributed to the characteristics of an object with dimension (size and shape); but also force and gravity (how we perceive changes happen to this object); and motion and movement (how we perceive the object behaves). These extramusical associations can be readily explained by psychophysical behaviour in the way humans perceive physical stimuli. According to investigations by Eitan et al. (2008), and Lipscomb and Kim (2004), loudness changes correlates cognitively and perceptually with vertical motion and is probably acquired through experience. The experience of larger objects and movements tends to generate more energy, and therefore louder sound. In addition, spatial height is correlated with physical size and with quantity, as illustrated in the "up is more" metaphor (Lakoff \& Johnson, 1980). Thus, an indirect loudness-height association may be generated since both are associated with physical size. This association is supported in my findings, with the dimension-size domain figuring most prominently for dynamics. From such explanations it is possible to see how technical vocabulary - pressure, waves, intensity - might evolve into descriptive language - hold back, swell, build up - describing musical goals in playing. Even in this one musical topic, there is good reason for why a teacher may choose metaphor to visualise, 
clarify and encapsulate the anticipated sound, rather than providing a complex description of its objective state.

That structural and experiential relationships exist between the sound stimulus and the perception of it, is at least one explanation for conventional metaphors used in music instruction where connections seem "more than associative" (Eitan \& Rothschild, 2011). This may even explain the predominance of colour as a source domain for tone, given the close kinship of colour perception and tone perception (see Gunther, 2012). The domains that appear correlated in experience and that share deep relational structures with specific musical topics, possibly function as models rather than deep imaginings (Gentner \& Bowdle, 2008).

Psychophysical cues in music are also known to arouse felt emotion. If sensitivity to emotion in music is a response to psychophysical dimensions of sound, and if emotion is known to be an entailment of musical expression, is this made explicit through metaphors used by music teachers to engage students in expressive playing? This study suggests not, and brings a different perspective to the claim of Juslin et al. (2004) that the usefulness of metaphor in music teaching is primarily in connecting the emotional content of music. I propose that while music may well engage emotion directly, neither emotive language nor reference to felt emotional content of the music are significant factors in instructional language used to elicit musically expressive performance. Across the 80 hours of transcriptions, there were single references to joy, disappointment, surprise, longing, and loving, and the word emotion itself was used once. If musical expression has a close connection to emotion, it may rarely surface explicitly or implicitly in a teacher's verbal instructions.

While emotion is shown in this study to correlate with particular acoustic and temporal properties (e.g., slow, descending minor intervals), there is other research that suggests that similar acoustic properties in the music of other cultures are not articulated verbally as emotion (Feld, 1981). Therefore, a credible explanation is that emotional responses are passed from one generation to the next, from parent to child, from teacher to student, as part of enculturation. In this way, this study also supports conclusions of Juslin and Lindström (2010) that psychophysical relations between acoustic properties and composed features most probably reflect cultural conventions developed over the long course of music's history.

This brings another dimension to what underlies motivations for metaphorical associations that must take into account the seeming paradox in the human condition that not all cultures experience the body, or its relationship to the external world, in the same way. By way of example of this complex view, while in western English-speaking environments we express our experience of music primarily in linguistic terms of space and motion, this vocabulary does not apply universally. For example, in the African language of Bantu, the high/low opposition is described as small/great (Tracey, 1948); and even in a language as closely related to English as French, the equivalent of high is "aigu", meaning sharp, pointed, piercing, keen, penetrating, screaming (Dubois, 1981, p. 19), and low is "grave", meaning sedate, solemn, important, weighty (Dubois, 1981, p. 300). This concurs with the view expressed by Lakoff and Johnson (1999) that spatial-relations concepts vary across languages. Lakoff and Johnson propose that lexical differences across languages may have to do with differences in conventional imagery across cultures, giving rise to different linguistic expressions of those mappings.

Further lexical differences are described by Shayan, Ozturk, and Sicoli (2011). They demonstrate that pitch differences expressed in English as high-low (vertical space) are expressed 
differently by Farsi and Zapotec speakers. They show that in each of these languages, lowfrequency sounds were described as thick sounds and high-frequency sounds as thin and that vocabulary for pitch also crosses over to the description of amplitude (loudness): "Thick" could also refer to loud sounds and "thin" to quiet sounds. It can be seen how these correlations contrast with languages like English that privilege a high-low verticality metaphor to talk about pitch. These findings, Shayan et al. suggest, show that "pitch perception is a dimension of our sense of hearing that can be conceptualized in different ways" (2011, p. 104), giving more weight to the argument that even associations in musical sound that appear biologically motivated, may be culturally bound and this may be so even in terms of how we experience our bodies, how we physically and psychologically locate ourselves in the world, and what intersensory experiences may present themselves to us, as Deutscher (2010) advances.

Metaphors motivated by cultural conventions are most evident in expressions that are highly conventional and clichéd because they may derive from, for example, 18th or 19th century thinking about music. These include references to feminine and masculine sound: "A masculine theme is louder and more angular. A feminine theme is softer and sweeter" [Regarding Haydn's music]; "There are feminine endings and masculine endings"; "The character needs to be stronger, more masculine, more extrovert".

This discussion has illuminated reasons and motivations for metaphor usage, inviting further investigation into metaphors used in real-life music instruction, laying the premise for why knowledge and awareness of metaphor matters in education settings that increasingly involve speakers from different language and cultural backgrounds. Ways of perceiving and conceiving the sounds of music are interconnected and evolve for a community of people over time, making music a social and cultural "product" as much as a "felt" psychophysical experience.

\section{Conclusions and implications for music pedagogy}

Overall, the metaphor identified in the study can be described as contextualised, prosaic and dynamic, similar to other educational discourse. However, its interactional mode has significant points of departure. Mainly, verbal communication in music instruction is not contingent on the usual demands of spoken interaction (i.e. question/ response); it is contingent on physical responses. Mostly, the teachers' remarks were delivered in short utterances made coherent by the student playing their response. It occurred most commonly as feedback to playing a passage and was rarely used to initiate playing. Commonly more deliberate, creative use of metaphor occurred after the technical aspects of note learning were mastered (e.g. fingering), and when the student was familiar enough with the piece to attempt shaping and polishing for performance. Metaphor in the context of music instruction is therefore largely monologic, interspersed with music, often imperative, imploring, and, while mostly prosaic, can be at times poetic.

A compelling strategy for the use of metaphor in music instruction is that it gives meaning to the process of thinking musically and enriches "the palette of expressive nuances" available to the practicing musician (Eitan \& Rothschild, 2011, p. 465). In relation to technical aspects, these associations are thought to stimulate the sensorimotor experience of playing and aid memory and internalisation. 
The deliberate and creative use of metaphor and analogy, in particular, supports pedagogical claims that metaphor and analogy work to build relationships important to the learning environment through shared experience (working "between the spaces" in Cameron's (2003) terms), and the perception that metaphor may make a difference between competence and excellence in teaching and learning music (Schippers, 2006). The way we see music, move it, touch it, taste it, and even hear it according to other sounds in the environment demonstrates strong motivational source domains for teaching and learning about the expressive features of sound. Such resources of language are powerful agents in the sharing of knowledge, understanding, and aesthetic appreciation; to the point that metaphor has the capacity to broaden the experience of what musical sound entails for the player or listener. In a modest way, this enriches our understanding of music performance as requiring not only an instrument and technical skills, but a body and mind that is fully engaged in music-making by imagining, sensing, and enacting the world around us.

\section{References}

Barten, S. S. (1998). Speaking of music: The use of motor-affective metaphors in music instruction. Journal of Aesthetic Education, 32(2), 89-97. doi:10.2307/3333561

Bhatara, A., Tirovolas, A. K., Duan, L. M., Levy, B., \& Levitin, D. J. (2011). Perception of emotional expres- sion in musical performance. Journal of Experimental Psychology, 37(3), 921-934. doi:10.1037/a0021922 2011

Blakemore, C., \& Jennett, S. (Eds.). (2001). The Oxford companion to the body. New York, NY: Oxford University Press.

Cacciari, C. (2008). Crossing the senses in metaphorical language. In R. W. Gibbs (Ed.), The Cambridge handbook of metaphor and thought (pp. 425-443). New York, NY: Cambridge University Press.

Cameron, L. (2003). Metaphor in educational discourse. London, UK: Continuum.

Cameron, L., \& MetNet Group. (2006). Metaphor analysis project. Retrieved from $\mathrm{http} / / /$ creet.open.ac.uk/projects/metaphor\%2Danalysis/procedure.cfm?subpage=discoursedata

Cortazzi, M., \& Jin, L. (1999). Bridges to learning: Metaphors of teaching, learning and language. In L. Cameron \& G. Low, Researching and applying metaphor (pp. 149-176). Cambridge, UK: Cambridge University Press.

Coutinho, E., \& Cangelosi, A. (2009). The use of spatio-temporal connectionist models in psychological studies of musical emotions. Music Perception, 27(1), 1-15.

Coutinho, E., \& Dibben, N. (2012). Psychoacoustic cues to emotion in speech prosody and music. Cognition \& Emotion, 27(4), 658-684. doi:10.1080/02699931.2012.732559 
Deutscher, G. (2010). Through the language glass: Why the world looks different in other languages. New York, NY: Picador.

Dubois, M. (1981). Dictionnaire moderne Français Anglais. Paris, France: Librairie Larousse.

Eitan, Z., \& Granot, R. Y. (2006). How music moves: Musical parameters and listeners' images of motion music perception. Music Perception, 23(3), 221-247.

Eitan, Z., \& Rothschild, I. (2011). How music touches: Musical parameters and listeners' audio-tactile metaphorical mappings. Psychology of Music, 39(4), 449-467.

doi:10.1177/0305735610377592

Eitan, Z., Schupak, A., \& Marks, L. E. (2008). Louder is higher: Cross-modal interaction of loudness change and vertical motion in speeded classification. In K. Miyazaki, Y. Hiraga, M. Adachi, Y. Nakajima \& M. Tsuzaki (Eds.), Proceedings of the 10th International Conference on Music Perception and Cognition (pp. 1-10). Adelaide, Australia: Causal Productions.

Feld, S. (1981). Flow like a waterfall: The metaphors of Kaluli musical theory. Yearbook for Traditional Music, 13, 22-47.

Gentner, D., \& Bowdle, B. (2008). Metaphor as structure-mapping. In R. W. Gibbs (Ed.), The Cambridge handbook of metaphor and thought (pp. 109-128). New York, NY: Cambridge University Press.

Gibbs, R. W. (2002). A new look at literal meaning in understanding what is said and implicated. Journal of Pragmatics, 34(4), 457-486.

Gibbs, R. W. (2008). Metaphor and thought: The state of the art. In R. W. Gibbs (Ed.), The Cambridge handbook of metaphor and thought (pp. 2-13). New York, NY: Cambridge University Press.

Goatly, A. (1997). The language of metaphors. London, UK: Routledge.

Gunther, L. (2012). The physics of music and color. New York, NY: Springer.

Juslin, P. N. (2003). Five facets of musical expression: A psychologist's perspective on music performance. Psychology of Music, 31(3), 273-302. doi:10.1177/03057356030313003

Juslin, P. N., Friberg, A., Schoonderwaldt, E., \& Karlsson, J. (2004). Feedback learning of musical expres- sivity. In A. Williamon (Ed.), Musical excellence: Strategies and techniques to enhance performance (pp. 247-270). Oxford, UK: Oxford University Press.

Juslin, P. N., \& Lindström, E. (2010). Musical expression of emotions: Modelling listeners' judgements of composed and performed features. Music Analysis, 29, 334-364.

Juslin, P. N., \& Persson, R. S. (2002). Emotional communication. In R. Parncutt \& G. E. McPherson (Eds.), The science and psychology of music performance: Creative strategies for teaching and learning (pp. 219-236). New York, NY: Oxford University Press. 
Juslin, P. N., \& Sloboda, J. A. (2001). Music and emotion: Theory and research. Oxford, UK: Oxford University Press.

Karlsson, J., Liljeström, S., \& Juslin, P. N. (2009). Teaching music expression: Effects of production and delivery of feedback by teacher vs. computer on rated feedback quality. Music Education Research, 11(2), 175-191. doi:10.1080/14613800902924532

Kövesces, Z. (2010). Metaphor: A practical introduction. New York, NY: Oxford University Press.

Laukka, P. (2004). Instrumental music teachers' views on expressivity: A report from music conservatoires. Music Education Research, 6(1), 45-56. doi:10.1080/1461380032000182803 Lakoff, G., \& Johnson, M. (1980). Metaphors we live by. Chicago, IL: University of Chicago Press.

Lakoff, G., \& Johnson, M. (1999). Philosophy in the flesh. New York, NY: Basic Books.

Lindström, E., Juslin, P. N., Bresin, R., \& Williamon, A. (2003). Expressivity comes from within your soul: A questionnaire study of music students' perspectives on expressivity. Research Studies in Music Education, 20(1), 23-47. doi:10.1177/1321103X030200010201

Lippman, E. A. (1977). A humanistic philosophy of music. New York, NY: New York University Press.

Lipscomb, S. D., \& Kim, E. M. (2004). Perceived match between visual parameters and auditory correlates: An experimental multimedia investigation. In S. Lipscomb, R. Ashley, R. Gjerdingen \& P. Webster (Eds.), Proceedings of the 8th International Conference on Music Perception \& Cognition. Retrieved from http://www.lipscomb.umn.edu/docs/LipscombKim_ICMPC8_proceedings.pdf

Pfaffmann, C. (2017). Human sensory reception. Encyclopaedia Britannica. Retrieved from https://www. britannica.com/science/human-sensory-reception

Schippers, H. (2006). “As if a little bird is sitting on your finger ...”. Metaphor as a key instrument in the education of professional musicians. International Journal of Music Education, 24(3), 209-217. doi:10.1177/0255761406069640

Schippers, H. (2010). Facing the music: Shaping music education from a global perspective. Oxford, UK: Oxford University Press.

Shayan, S., Ozturk, O., \& Sicoli, M. A. (2011). The thickness of pitch: Crossmodal metaphors in Farsi, Turkish, and Zapotec. Senses \& Society, 6(1), 96-105.

doi:10.2752/174589311X12893982233911 Sheldon, D. A. (2004). Listeners' identification of musical expression through figurative language and musical terminology. Journal of Research in Music Education, 52(4), 357-368.

Sloboda, J. A. (1996). The acquisition of musical performance expertise: Deconstructing the "talent" account of individual differences in musical expressivity. In K. A. Ericsson (Ed.), The road to excellence: The acquisition of expert performance in the arts and sciences, sports and games (pp. 107-126). Mahwah, NJ: Lawrence Erlbaum Associates. 
Sloboda, J. A. (2008). Science and music: The ear of the beholder. Nature, 454(7200), 32-33. doi:10.1038/454032a

Steen, G. J., Dorst, A. G., Herrmann, J. B., Kaal, A. A., Krennmayr, T., \& Pasma, T. (2010). A method for linguistic metaphor identification: From MIP to MIPVU. Amsterdam, the Netherlands: John Benjamins B.V.

Swanwick, K. (1979). A basis for music education. Windsor, UK: NFER-Nelson.

Thiemel, M. (2016). Dynamics. In Grove Music Online: Oxford Music Online. Retrieved from http://www.oxfordmusiconline.com/subscriber/article/grove/music/08458

Tracey, H. (1948). Ngoma: An introduction to music for Southern Africans. London, UK: Longmans Green.

Van Zijl, A., \& Sloboda, J. A. (2010). Performers' experienced emotions in the construction of expressive musical performance: An exploratory investigation. Psychology of Music, 39(2), 196-219. doi:10.1177/0305735610373563

Woody, R. H. (1999). The relationship between advanced musicians' explicit planning and their expressive performance of dynamic variations in an aural modeling task. Journal of Research in Music Education, 47(4), 331-342. doi:10.2307/3345488

Woody, R. H. (2000). Learning expressivity in music performance: An exploratory study. Research Studies in Music Education, 14(1), 14-23. doi:10.1177/1321103X0001400102

Woody, R. H. (2002). Emotion, imagery and metaphor in the acquisition of musical performance skill. Music Education Research, 4(2), 213-224.

doi:10.1080/1461380022000011920

\section{Author Biography}

Jocelyn Wolfe is an Adjunct Research Fellow with Queensland Conservatorium Research Centre, Griffith University, in Australia. She has worked extensively in the university environment supporting students in their academic music studies. Beyond her $\mathrm{PhD}$ study on metaphor and music instruction, her research explores relationships between music and architecture, and music and society. She continues to investigate connections between language, music, sound, and culture. 
